\title{
Quantitating Non-Zero Autocorrelation to Determine Moran's I Coefficients for Mapping Clustering Tendencies of Fast Food Restaurants in Lower SES Neighborhoods in Hillsborough County, Florida
}

Nathanael Stanley, Samuel Alao and Benjamin Jacob*

Department of Global Health, College of Public Health, University of South Florida, Tampa, FL, USA

\begin{abstract}
This research utilizes a similar method, using what may prove to be more precise spatial statistics to determine clustering tendencies and economic data to assess their location in relation to low income areas. It is also important to note that race/ethnicity is not included in this research; rather it focuses on designation of population density and persons living at or below poverty level. This research provides a way to spatially determine if fast food restaurants are more prominent in low socioeconomic areas.
\end{abstract}

Keywords: Mapping; Auto correlation; Fast food restaurants; Socioeconomic areas

\section{Introduction}

According to the Federation of American Societies for Experimental Biology Life Sciences Research Report, food insecurity exists when "the availability of nutritionally adequate and safe foods or the ability to acquire acceptable foods in socially acceptable ways is limited or uncertain". While some research on the identification of food deserts highlight accessibility factors such as walkability to fresh produce supermarkets $[1,2]$, perceived accessibility of fresh produce markets [2,3], and proximity of fresh produce to low SES areas [47], there is little research that addresses the spatial clustering of fast food restaurants, and whether the clustering is focused in areas of low socioeconomic standing. This research focuses on the geographic location of major fast food restaurants using Moran's I coefficient to identify positive spatial autocorrelation to determine where spatial clustering occurs, if any.

Although the identification of the social factors that influence the individual's perceived and actual spatial accessibility to healthy, fresh food is very important, it is also important that we observe the location of the food sources to see how city infrastructure can contribute to the spatial clustering of unhealthy food stores. There is a general assumption that fast food chains build more of their restaurants in areas assumed to be lower in socioeconomic status. Research by Block, Scribner, and DeSalvo [8] used geographic information software to spatially locate all fast food restaurants within New Orleans, Louisiana in 2001. They used multiple regression, spatial buffers of 0.5 and 1.0 miles, fast food location density, and medium household income to test their hypothesis that there are higher densities of fast food restaurants in areas of medium to low income, where they found an association with fast food restaurant clustering in low income areas [8].

Hypothesis: There are higher spatial clustering of fast food restaurants in lower socioeconomic areas of Hillsborough County, FL.

\section{Methods}

\section{Locating fast food restaurants}

To identify fast food restaurants, we searched for the major fast food restaurants by name in Google Earth: "[name of restaurant] in Hillsborough County Florida”. Each positively identified fast food restaurant received a placemark that identified their latitude and longitude. Google Earth identified a total of 357 fast food restaurants, but due to the uncertainty that these restaurants were still open, each point was cross referenced in Google Maps. After the cross reference, a total of 14 restaurants were removed from the dataset due to the locations being permanently closed, leaving a total of 343 fast food restaurants. Figure 1 shows the spatial association of the fast food restaurants, and Figure 2 shows the frequency of each type of fast food restaurant included in this research. The placemarks were then exported as a .kml file. Using ArcMap 10.3, the .kml file of GPS-located fast food restaurants was converted into a layer file, and the points exported as a shapefile to show their spatial location in the ArcMap program. Data showing major roads in Hillsborough County, FL, as well as the county boundary, came from the Florida Transportation Plan (FTP) open access corporate data [9].

\section{Socioeconomic factors}

In order to determine areas of low socioeconomic standing, we used the 2010-2014 American Community Survey (ACS) 5YR dataset. There are 1YR and 3YR datasets of the ACS, but the 5YR dataset is the most reliable of the three, accounts for 60 months of data collection, and is best used for small population sizes [10]. The ACS spatial data accounts for the entire United States, so Hillsborough County, Florida needed to be selected by identifying the ID for Florida, and then the ID for Hillsborough County, and creating each as its own layer separate from the larger dataset. Once Hillsborough County, Florida had its own shapefile, the poverty data was joined to the shapefile by the unique GEOID. The variable B17001e2 from the newly joined ACS Poverty dataset identified the number of persons who were living at or below the poverty line for the past 12 months.

*Corresponding author: Benjamin Jacob, Department of Global Health, College of Public Health, University of South Florida, Tampa, FL, USA, Tel: 8139749784; E-mail: bjacob1@health.usf.edu

Received November 04, 2016; Accepted November 17, 2016; Published November 21, 2016

Citation: Stanley N, Alao S, Jacob B (2016) Quantitating Non-Zero Autocorrelation to Determine Moran's I Coefficients for Mapping Clustering Tendencies of Fast Food Restaurants in Lower SES Neighborhoods in Hillsborough County, Florida. J Remote Sensing \& GIS 5: 179. doi: 10.4179/2469-4134.1000179

Copyright: $\odot 2016$ Stanley N, et al. This is an open-access article distributed under the terms of the Creative Commons Attribution License, which permits unrestricted use, distribution, and reproduction in any medium, provided the original author and source are credited. 
Citation: Stanley N, Alao S, Jacob B (2016) Quantitating Non-Zero Autocorrelation to Determine Moran's I Coefficients for Mapping Clustering Tendencies of Fast Food Restaurants in Lower SES Neighborhoods in Hillsborough County, Florida. J Remote Sensing \& GIS 5: 179. doi: $10.4179 / 2469-4134.1000179$

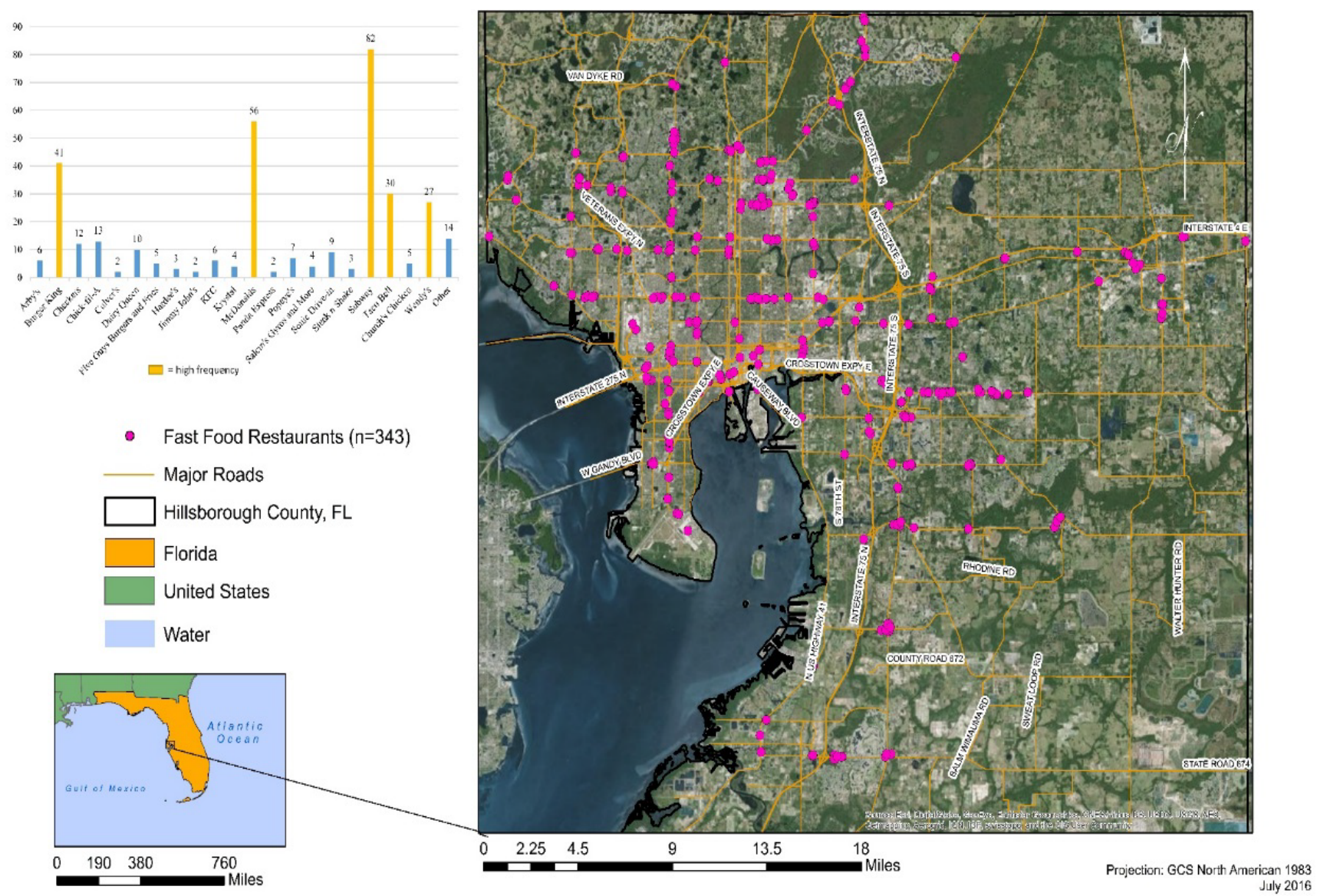

Figure 1: Selection of Major Fast Food Restaurants in Hillsborough County, FL.

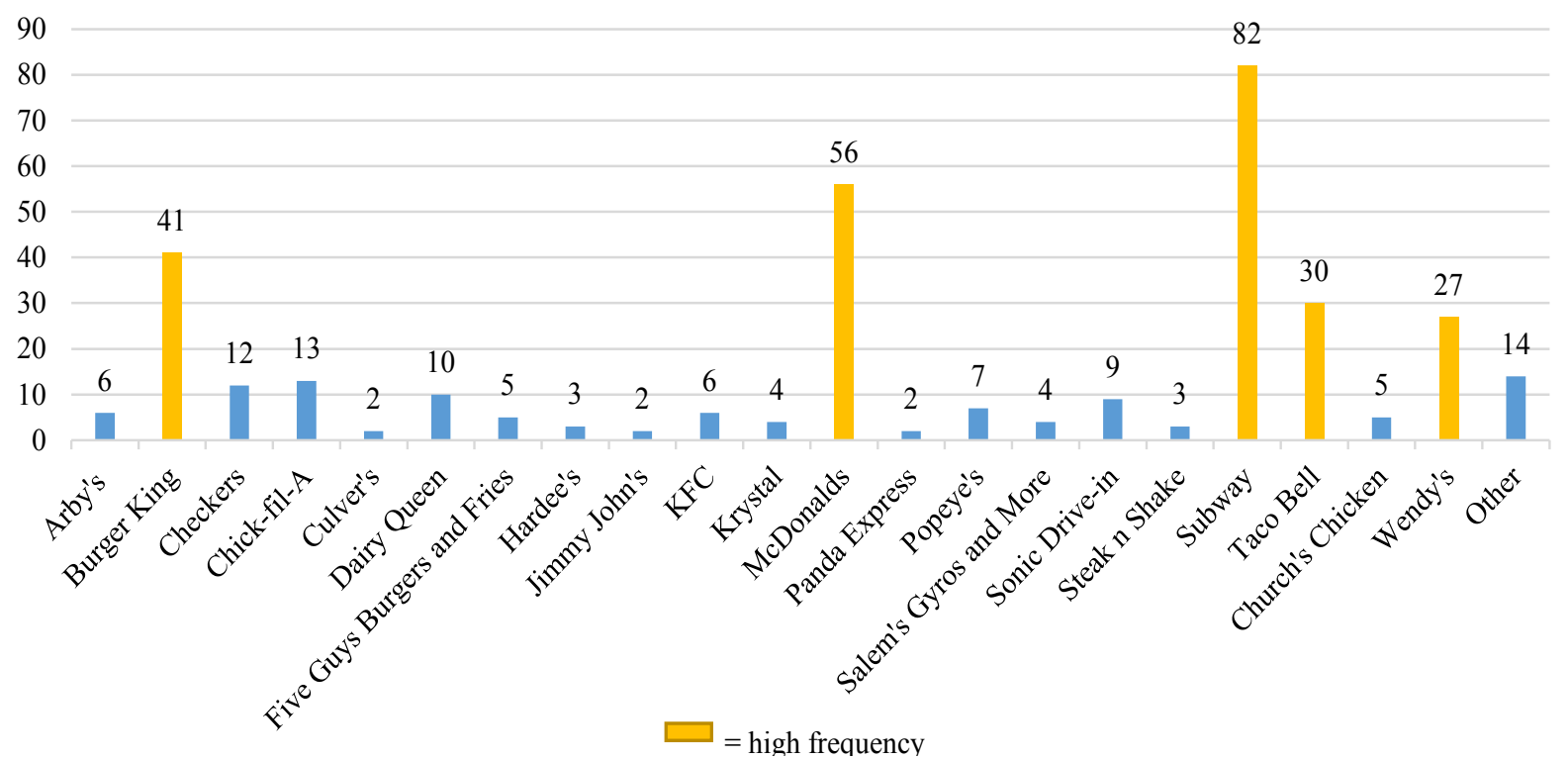

Other refers to restaurants for which there were only 1 identified: A\&W, Blimpie, Dunkin Donuts, Royal Sweets, Peking Fast Food, Austin Center Café, Pollo Tropical, Zaxby's, Quiznos, Red Burrito, Qdoba Mexican Grill, D\&D Delights, and Long John Silvers. There may be more than one for any of these restaurants, so these numbers are potentially underestimated.

Figure 2: Frequencies of Selected Fast Food Restaurants in Hillsborough County, FL. 
Citation: Stanley N, Alao S, Jacob B (2016) Quantitating Non-Zero Autocorrelation to Determine Moran's I Coefficients for Mapping Clustering Tendencies of Fast Food Restaurants in Lower SES Neighborhoods in Hillsborough County, Florida. J Remote Sensing \& GIS 5: 179. doi: $10.4179 / 2469-4134.1000179$

Page 3 of 6

\section{Population density}

Spatial data indicating population density was retrieved from the Florida Geographic Data Library (FGDL). The dataset used, CENACS 2014, represents census block group data from 2010 joined with ACS 2010-2014 data by the University of Florida GeoPlan Center in Gainesville, FL [11]. The variable DEN_POP was used in order to identify the population density with each block group. DEN_POP represents the total population of the block group census tract divided by the acreage of that block group [11]. The GPS-located fast food restaurants were placed on top of the CENACS 2014 shapefile in order to observe the spatial correlation with fast food and population density in Hillsborough County, Florida. Densities ranged from low, mid-low, medium, mid-high, and high densities. In order to identify the frequency of fast food restaurants by population density, a new shapefile was created out of the CENACS_2010 shapefile by using select by attributes and the following structure query language (SQL):

- Low density: DEN_POP $\leq 3.47$

- Low to mid-low density: DEN_POP $\leq 7.73$

- Mid-low to high density: DEN_POP $\geq 3.48$

- Medium to high density: DEN_POP $\geq 7.38$

- Mid-high to high density: DEN_POP $\geq 12.49$

- High density: DEN_POP $\geq 22.70$

In order to identify which fast food restaurants were within the selected census tracts, we used the select by location feature to select only the fast food restaurants that intersect with each of the new layer files created with the aforementioned SQL.

\section{Statistical methodology}

In order to determine spatial clustering of the GPS-located fast food restaurants, there needed to be a spatially-defined sociodemographic variable associated with those points. To achieve this, we added the variable B17001e2 (the number of persons who are living at or below the poverty line for the past 12 months) from the ACS Poverty dataset to the fast food shapefile as a new field in the attribute table. In this way, the fast food points located in any given census tract were also associated with the number of people in that census tract who identified as living at or below the poverty line in the past twelve months. The ACS determined poverty status of the individual by comparing 12 months of household income to the poverty threshold that household falls under, which vary by the number of people living in the house [12].

The fast food GPS dataset was sorted in an ascending pattern based on based on numbers of people living below the poverty line in geo-sampled locations within Hillsborough County. The derived epidemiologic dataset was stratified into two geo-referenced groups of population proportions based on their distribution 2 standard deviations below and above the median of number of people living below poverty line. In so doing, the number of individuals above two standard deviations from the median ( $>1164$ people living below poverty line; obs $=87$ ) were inferred to be in the low socio-economic geolocations; while individuals at the lower spectrum of 2 standard deviations below the median $(<328$ people living below poverty line; obs $=88$ ) were taken to be in the higher socioeconomic zones. Additionally, the assumption for spatial independence was tested for elucidative epidemiologic observations employing the Pearson product moment correlation coefficient (Moran's Index).

Spatial autocorrelation techniques (Moran's Index) have been applied as diagnostic tool for model misspecifications, spatial nonhomoscedasticity and outliers in remote sensed eco-epidemiologic datasets $[13,14]$. Likewise, Moran's Index is used to determine if the dependent variables are clustered or randomly distributed within a geographic space [15]. We used PROC VARIOGRAM in SAS 9.4 to generate Moran's Index by computing cross mean of Euclidean inter-site distances between values that are geographic neighbors. Similarly, the LAGDISTANCE OPTION indicates the neighborhood size in the PROC VARIOGRAM procedure, which is important in the computation of autocorrelation index. It is of note that lagdistance depends on the dataset and our goal is to create a variogram that invariably provides best estimates of spatial dependence for the underlying stochastic process. The compute statement allowed for row averaging of Binary spatial weights within the autocorrelation statistical process needed for the construction of Moran's coefficient (an equivalent of regression slope for the Moran's scatter plot).

\section{Results}

\section{Spatial clustering}

Based on the spatial autocorrelation calculations, there is higher spatial clustering of fast food restaurants in areas of low socioeconomic standing than those with higher socioeconomic standing. PROC VARIOGRAM SAS OUTPUT revealed an observed (Moran's $\mathrm{I}=0.192 ; \mathrm{P}=0.0002)$ for fast food restaurants located in high income neighborhoods (Table 1); while fast food restaurants situated in low income geo-locations revealed an observed (Moran's $I=0.266$; $\mathrm{P}=<0.0001$ ) (Table 2). The result demonstrated weak positive spatial autocorrelation for both high and low income neighborhoods in the regressive model. However, based on these analyses, fast-food locations tend (138.5\%) to be situated in low income neighborhoods compared to high income georeferenced demographic geolocations within Hillsborough County, Florida within a comfortable statistical significance level.

Of the 343 fast food restaurants identified in this analysis, 61 (18\%) are located in larger businesses, such as the Tampa International Airport $(n=2)$, the University of South Florida $(n=2)$, University of Tampa $(n=1)$, Walmart or Walmart Supercenter $(n=2)$, Tampa General Hospital $(n=2)$, or various shopping plazas $(n=52)$. Figure 3

\begin{tabular}{|c|c|c|c|c|c|c|}
\hline Assumption & Coefficient & Observed & Expected & Std Dev & $\mathbf{Z}$ & $\operatorname{Pr}>|Z|$ \\
\hline Normality & Moran's I & 0.192 & -0.0116 & 0.0543 & 3.75 & 0.0002 \\
\hline Normality & Gary's c & 0.814 & 1.0000 & 0.0569 & -3.27 & 0.0011 \\
\hline \multicolumn{7}{|c|}{ Table 1: Autocorrelation Statistics - High Income Areas. } \\
\hline Assumption & Coefficient & Observed & Expected & Std Dev & $\mathbf{Z}$ & $\operatorname{Pr}>|Z|$ \\
\hline Normality & Moran's I & 0.266 & -0.012 & 0.0476 & 5.58 & $<.0001$ \\
\hline Normality & Gary's c & 0.726 & 1.000 & 0.0503 & -5.44 & $<.0001$ \\
\hline
\end{tabular}

Table 2: Autocorrelation Statistics - Low Income Areas. 
Citation: Stanley N, Alao S, Jacob B (2016) Quantitating Non-Zero Autocorrelation to Determine Moran's I Coefficients for Mapping Clustering Tendencies of Fast Food Restaurants in Lower SES Neighborhoods in Hillsborough County, Florida. J Remote Sensing \& GIS 5: 179. doi: $10.4179 / 2469-4134.1000179$

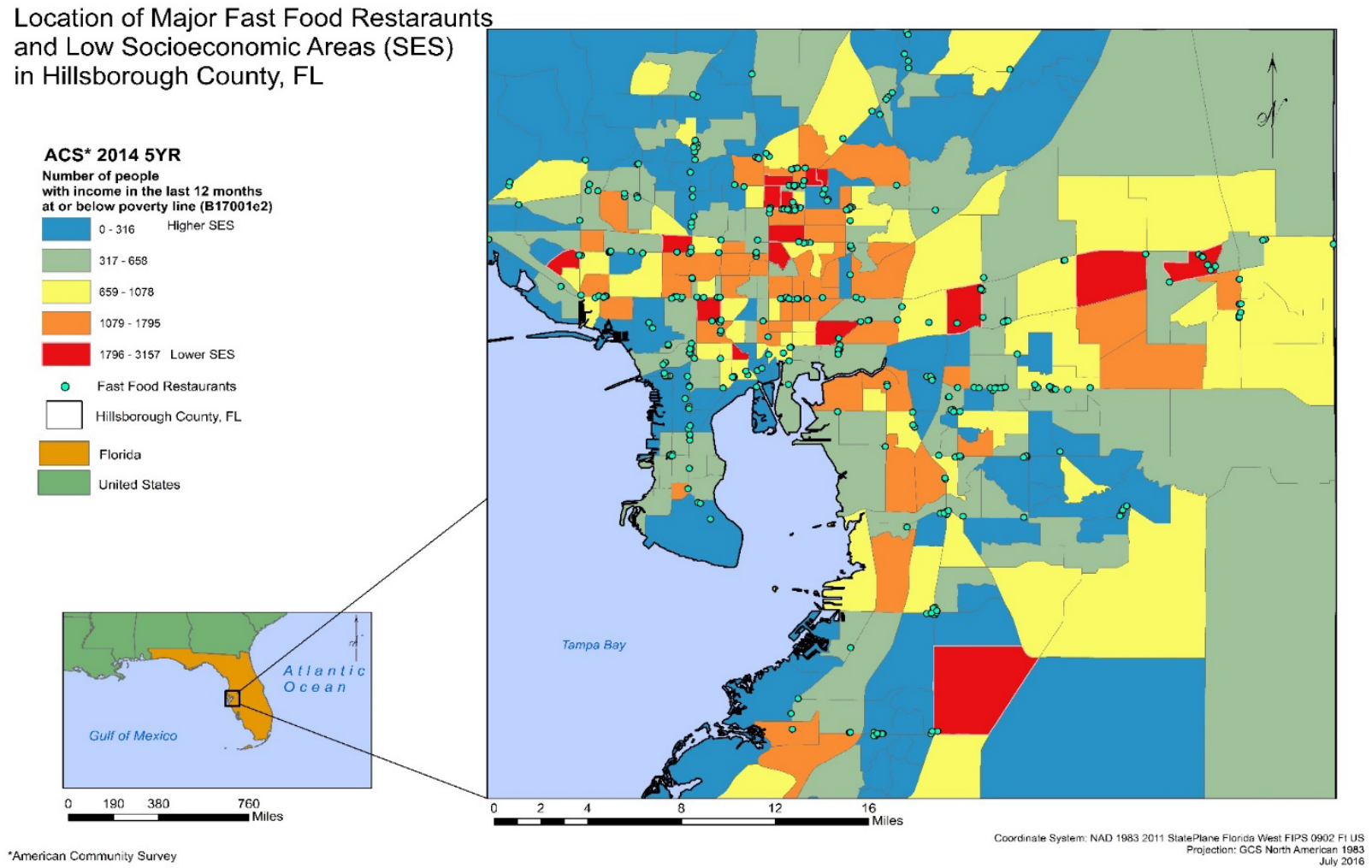

Figure 3: Location of Major Fast Food Restaurants and Low Socioeconomic (SES) Areas in Hillsborough County, FL.

shows the location of the fast food restaurants in association with areas of low socioeconomic standing, and Figure 4 shows the frequency of fast food restaurants included in this research by city in Hillsborough County, Florida.

\section{Population density}

We hypothesized that population density may contribute to a higher number of persons identifying poverty status in the census tracts with the higher number of respondents. Figure 3 shows the population densities by block census group, overlaid with the GPS-located fast food restaurants. There are six levels of population density analyzed for how many fast food restaurants intersect each density level. Table 3 shows the percentage of the total number of fast food restaurants for each level of population density. Based on the percentages of the total number of fast food restaurants, it is clear that population density does not contribute to a higher number of persons identifying poverty status; $79 \%$ of the fast food restaurants reside in areas with low to midlow population density areas, and only $21 \%$ of the fast food restaurants reside in medium to high population density areas of Hillsborough County, Florida.

\section{Limitations of this Research}

This research does not account for all fast food restaurants within Hillsborough County. Fast food local to Florida, or this area of Florida, may not be entirely accounted for, so the data is most likely underreported. This research does not include farmer's markets and low-cost fresh produce markets, and does not discuss nutritional content compared between fast food and low cost, fresh produce markets. Inclusion of low-cost, fresh produce markets may serve to identify more precise areas of fast food spatial clustering that occur outside of defined distances from the fresh produce markets.

\section{Discussion}

There is no single factor that determines a food desert; not just ethnicity, not just income, not just property value. Rather, all these factors are embedded within an ongoing relationship that contributes to health disparity. In a study by Ref. [16], researchers similarly found higher frequencies of fast food restaurants in low income neighborhoods in King County, WA. They hypothesized that non-major road density was also a factor for higher fast food restaurant density [17]. They also tested to see if property value was a factor, but were unable to make that connection [16]. However, lower property values are attractive to chain enterprises because they can build stores at a lower cost. It is possible that city planning has an effect on the frequency of fast food restaurants in a given neighborhood, city, or county.

In an attempt to account for the role that city planning might play regarding spatial clustering of fast food restaurants, Los Angeles County, California implemented at ban on fast food stores in 2008, called the "Los Angeles Fast-Food Ban". The ban was actually a restriction for fast food restaurants to build "stand alone" stores, which are essentially fast food stores that are not located within a larger business [18]. Sturm and Hattori [18] analyzed the effect that the fast food ban had on obesity and diet in the residents of Los Angeles, CA, but mention that the environmental changes to the city are slow, and will continue to be slow. There were several structural issues with the new policy, such as a $2 \%$ rate of new stores being built in South Los Angeles, the lack of city officials effectively enforcing the new policies, and a minimal decrease in obesity and diabetes [18].

The policy established by the "Los Angeles Food Ban" is one piece to 
Citation: Stanley N, Alao S, Jacob B (2016) Quantitating Non-Zero Autocorrelation to Determine Moran's I Coefficients for Mapping Clustering Tendencies of Fast Food Restaurants in Lower SES Neighborhoods in Hillsborough County, Florida. J Remote Sensing \& GIS 5: 179. doi: $10.4179 / 2469-4134.1000179$

Page 5 of 6

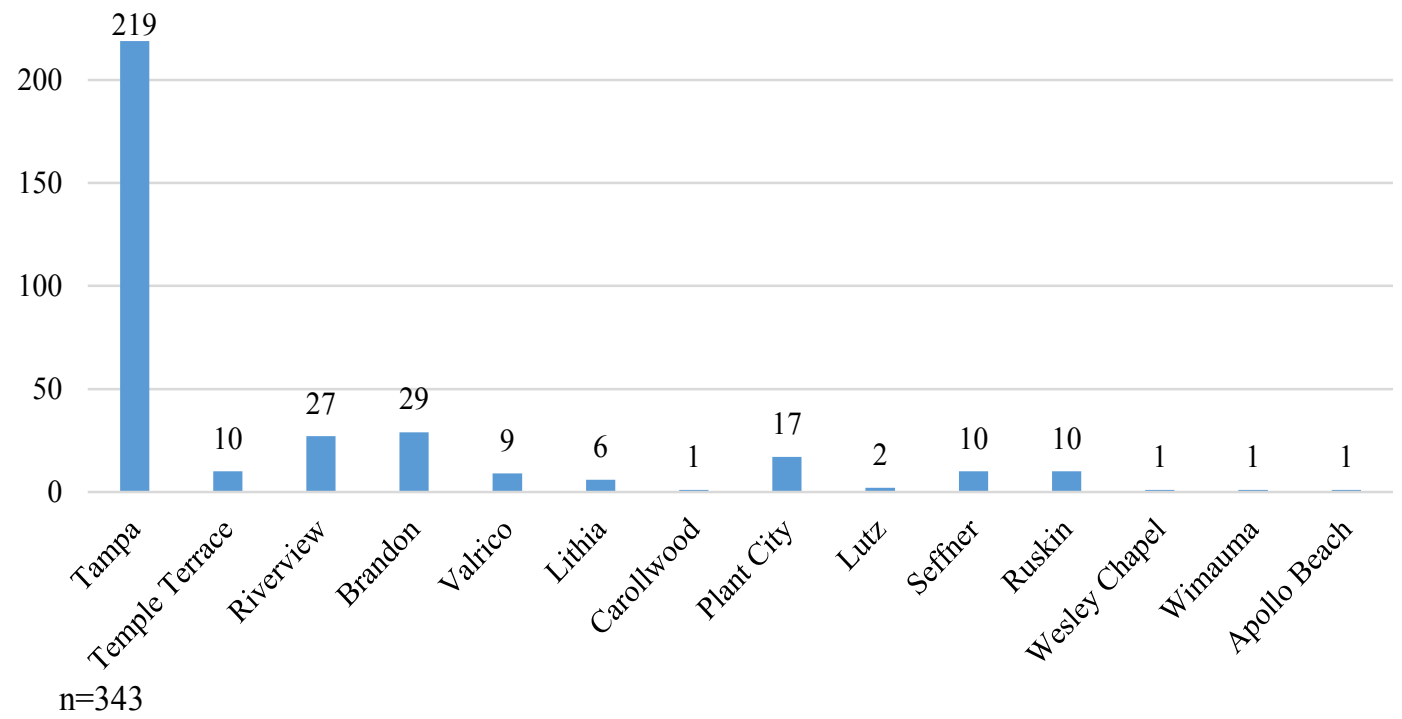

Figure 4: Frequency of Fast Food Restaurants by City in Hillsborough County, FL.

\begin{tabular}{|c|c|}
\hline Level of Population Density & Percentage of Fast Food Restaurants $(n=343)$ \\
\hline Low population density & $41.4 \% \quad n=142$ \\
\hline Low to Mid-Low population density & $79 \% \quad n=271$ \\
\hline Mid-Low to High population density & $58.6 \% \quad n=201$ \\
\hline Medium to High population density & $\mathrm{n}=72$ \\
\hline Mid-High to High population density & $3.2 \% \quad n=11$ \\
\hline High population density & $0 \% \quad \mathrm{n}=0$ \\
\hline
\end{tabular}

Percentages rounded to the nearest tenth

Table 3: Percentage of Fast Food Restaurants associated with Population Density.

the puzzle. Policy will inevitably have a role to play if city officials wish to make an environmental change that facilitates a healthy population. Based on information from the Florida Department of Business and Professional Regulation, fast food restaurants are required to obtain a Department of Business and Professional Regulation (DBPR) license to build a new store [18]. In essence, city governments allow the spatial clustering of fast food restaurants in low income areas because they lack any regulation that prohibits spatial clustering of those restaurants, coupled with the fact that these licenses provided by the State are not free. The capitalistic ideology of American society may also be a factor in the constant rise in obesity in the United States.

There is also a behavioral factor to address when attempting to identify contributing factors for fast food consumption, outside of their spatial location. In a study by Garza et al. [19], researchers found that impulsive eating at fast food restaurants was a common behavior for working adults. Based on their results, $67 \%$ of the participants said they ate at a fast food restaurant at least once within a 7 day period [19]. Research by Järvelä-Reijonen et al. [20] found that working adults in Finnland perceived high levels of stress, and suggest stress eating may be a reaction to increased amounts of stress. Some research suggests that an effect of stress is an increase in food consumption, epecially comfort food that is higher in sugar and carbohydrates [2124]. Stressors such as safety, economic security, and overall health are stressors that individuals living at or below the poverty level are more prone to deal with at any given time [25-27].

There is an intra-active nature in the economics of city planning, business development, and economic and nutritional disparity, and how they relate to individuals who deal with less than desirable wellness, poverty, and the exorbitant amount stress that goes along with them. To quote physicist Barad [28], "The world is a dynamic process of intraactivity in the ongoing reconfiguring of locally determinate causal structures with determinate boundaries, properties, meanings, and patterns of marks on bodies". Individuals and families who make below the poverty line often have no choice other than to live in an area where property value is low, thus resulting in lower cost of living. Although the consumption of fast food is not limited to people living near to below the poverty line, individuals falling within that demographic may be prone to utilize, even rely on, the low-cost food more often than people with a higher socioeconomic standing [29].

\section{References}

1. Jiao J, Moudon AV, Ulmer J, Hurvitz PM, Drewnowski A (2012) How to identify food deserts: measuring physical and economic access to supermarkets in King County, Washington. American Journal of Public Health 102: 32-39.

2. Kelly B, Flood VM, Yeatman H (2011) Measuring local food environments: An overview of available methods and measures. Health and Place 17: 1284-1293.

3. Caspi CE, Kawachi I, Subramanian SV, Adamkiewicz G, Sorensen G (2012) The relationship between diet and perceived and objective access to supermarkets among low-income housing residents. Social Science \& Medicine 75: 1254 1262.

4. Morland K, Filomena S (2007) Disparities in the availability of fruits and vegetables between racially segregated urban neighbourhoods. Public Health Nutrition 10: 1481-1489.

5. Powell LM, Slater S, Mirtcheva D, Bao Y, Chaloupka FJ (2007) Food store 
Citation: Stanley N, Alao S, Jacob B (2016) Quantitating Non-Zero Autocorrelation to Determine Moran's I Coefficients for Mapping Clustering Tendencies of Fast Food Restaurants in Lower SES Neighborhoods in Hillsborough County, Florida. J Remote Sensing \& GIS 5: 179. doi: $10.4179 / 2469-4134.1000179$

Page 6 of 6

availability and neighborhood characteristics in the United States. Preventive Medicine 44: 189-195.

6. Raja S, Chang X, Ma C, Yadav P (2008) Beyond Food Deserts: Measuring and Mapping Racial Disparities in Neighborhood Food Environments. Journal of Planning Education and Research 27: 469-482.

7. Zenk SN, Schulz AJ, Israel BA, James SA, Bao S, et al. (2005) Neighborhood racial composition, neighborhood poverty, and the spatial accessibility of supermarkets in metropolitan Detroit. American Journal of Public Health 95: 660-667.

8. Block JP, Scribner RA, DeSalvo KB (2004) Fast food, race/ethnicity, and income: A geographic analysis. American Journal of Preventive Medicine 27 : 211-217.

9. FDT (2016) Major Roads. Florida Department of Transportation, Innovation, Mobility and Economic Development, Florida, USA.

10. American Community Survey (ACS) (2015) When to Use 1-year, 3-year, or 5-year Estimates. US Department of Commerce, USA.

11. US Census Bureau (2013) 2010 Census Block Groups in Florida with Data from 2007-2011 American Community Survey (ACS). University of Florida GeoPlan Center, Gainesville, USA.

12. US Census Bureau (2015) American Community Survey and Puerto Rico Community Survey 2014 Definitions. US Department of Commerce, Washington DC, USA.

13. Jacob BG, Griffith DA, Mwangangi J, Gathings DA, Mbogo CC, et al. (2011) A Cartographic Analysis Using Spatial Filter Logistic Model Specifications for Implementing Mosquito Control in Kenya. Urban Geography 32: 263-300.

14. Lichstein J, Simons T, Shriner S (2002) Spatial autocorrelation and autoregressive models in ecology. Ecological Monographs 72: 445-463.

15. Waldhör T (1996) The spatial autocorrelation coefficient Moran's I under heteroscedasticity. Statistics in Medicine 15: 887-892.

16. Hurvitz PM, Moudon AV, Rehm CD, Streichert LC, Drewnowski A, et al. (2009) Arterial roads and area socioeconomic status are predictors of fast food restaurant density in King County, WA. International Journal of Behavioral Nutrition and Physical Activity 6: 46

17. Sturm R, Hattori A (2015) Diet and obesity in Los Angeles County 2007-2012
Is there a measurable effect of the 2008 "Fast-Food Ban"? Social Science \& Medicine 133: 205-211.

18. Florida DBPR (2016) What services require a State of Florida license? Department of Business and Professional Regulation, Florida, USA

19. Garza KB, Ding M, Owensby JK, Zizza CA (2016) Impulsivity and Fast-Food Consumption: A Cross-Sectional Study among Working Adults. Journal of the Academy of Nutrition and Dietetics 116: 61-68.

20. Järvelä-Reijonen E, Karhunen L, Sairanen E, Rantala S, Laitinen J, et al. (2016) High perceived stress is associated with unfavorable eating behavior in overweight and obese Finns of working age. Appetite 103: 249-258.

21. Groesz LM, McCoy S, Carl J, Saslow L, Stewart J, et al. (2012) What is eating you? Stress and the drive to eat. Appetite 58: 717-721.

22. Sinha R, Jastreboff AM (2013) Stress as a Common Risk Factor for Obesity and Addiction Obesity and Addiction: The Integral Role of Stress. Biological Psychiatry 73: 827-835.

23. Tryon M, DeCant R, Laugero K (2013) Having your cake and eating it too A habit of comfort food may link chronic social stress exposure and acute stressinduced cortisol hyporesponsiveness. Physiology \& Behavior 114: 32-37.

24. White BA, Horwath CC, Conner TS (2013) Many apples a day keep the blues away-daily experiences of negative and positive affect and food consumption in young adults. British Journal of Health Psychology 18: 782-798.

25. Evans GW, Kim P (2013) Childhood Poverty, Chronic Stress, Self-Regulation and Coping. Child Development Perspectives 7: 43-48.

26. Laraia B, Vinikoor-Imler LC, Siega-Riz AM (2015) Food insecurity during pregnancy leads to stress, disordered eating, and greater postpartum weight among overweight women. Obesity 23: 1303-1311.

27. Wadsworth M, Rindlaub L (2013) A longitudinal examination of the adaptation to poverty-related stress model: Predicting child and adolescent adjustment over time. Journal of Clinical Child \& Adolescent Psychology 42: 713-725.

28. Barad K (2008) Posthumanist performativity: Toward an understanding of how matter comes to matter. In: Alaimo S, Hekman S, Hames-Garcia M (eds.) Material Feminisms, Indiana University Press, Indiana, pp: 120-154.

29. Anderson SA (1990) Core indicators of nutritional state for difficult-to-sample populations. The Journal of Nutrition (USA) 120: 1557-1599. 